\title{
ATORES NÃO-ESTATAIS E A DEMOCRACIA NO BRASIL: O PROTAGONISMO DOS EMPRESAS DO VALE DO SILÍCIO NO EXERCÍCIO DA CIDADANIA
}

\section{NON-STATE ACTORS AND DEMOCRACY IN BRAZIL: THE ROLE OF COMPANIES IN THE SILICON VALLEY IN THE EXERCISE OF CITIZENSHIP}

\section{DANIELA MENENGOTI GONÇALVES RIBEIRO}

Doutora em Direito-Relações Econômicas Internacionais pela Pontifícia Universidade Católica de São Paulo (PUC/SP) com período de pesquisa (doutorado sanduíche) na Université Paris 1 - Panthéon-Sorbonne, França. Mestre em Direito-Relações Internacionais, pela Universidade Federal de Santa Catarina (UFSC). Professora do Programa de Pós-graduação em Ciências Jurídicas e da graduação em Direito da Unicesumar, Maringá/PR. Pesquisadora do Instituto Cesumar de Ciência, Tecnologia e Inovação (ICETI). ORCID: http://orcid.org/0000-0001-7621-8899

\section{FERNANDO NAVARRO VINCE}

Mestre em Ciência Jurídicas pela Unicesumar, Maringá/PR. Especialista em Direito do Estado pela Universidade Estadual de Londrina (UEL). Graduado em Direito pela Universidade Estadual de Londrina (UEL). Docente de Ensino Superior desde 2011. Coordenador do Curso de Direito da Faculdades Londrina/PR. Professor da Graduação em Direito da Faculdades Londrina. Professor de Direito Constitucional e Processual Civil dos programas de Pós-graduação Lato Sensu (Especialização) do Instituto de Direito Constitucional e Cidadania (IDCC) Londrina/PR e da Faculdade Alvorada, Maringá/PR. Membro do Grupo de Pesquisa (CNPq) Internacionalização do direito: dilemas constitucionais e internacionais contemporâneos. Advogado. ORCID: https://orcid.org/0000-0001-8621-0639 


\section{RESUMO}

O artigo analisa os impactos do uso cada vez mais frequenta da Internet no exercício da cidadania, e a tentativa da reforma eleitoral brasileira em atender essa realidade, colocando a rede como um dos principais meios de marketing eleitoral. No entanto, a atuação manipulada de atores não-estatais como a mídia, os partidos políticos e as empresas estrangeiras, amparada pela recente alteração na lei brasileira, que favoreceu o modelo de negócios das grandes plataformas digitais do Vale do Silício, têm violado compromissos básicos da democracia. Ao se valer de raciocínio dedutivo, por meio de pesquisa bibliográfica e documental, o artigo conclui que, embora o acesso à internet seja garantia à liberdade de expressão e informação, impor mais responsabilização às empresas contratadas e exigir maior transparência na rede a fim de se distinguir o real do manipulado, é fundamental tanto para o governo como para a sociedade civil, em defesa das liberdades civil e direitos políticos.

PALAVRAS-CHAVE: Atores não-estatais; Democracia; Internet; Reforma política.

\section{ABSTRACT}

The article analyzes the impact of the increasingly frequent use of Internet in the exercise of citizenship, and the attempt by the Brazilian electoral reform to meet this reality, putting the network as one of the principal means of marketing. However, the acting handled by non-State actors such as the media, political parties and foreign companies, bolstered by the recent change in Brazilian law, which favored the business model of the major digital platforms in Silicon Valley, have violated basic tenets of democracy. By the use of deductive reasoning, through bibliographical and documentary research, the article concludes that, although access to the internet should be a guarantee to freedom of expression and information, it needs to impose more accountability to its contractors and require greater transparency in the network in order to distinguish what is real from what is manipulated, this is crucial for both the Government and civil society in defending civil liberties and political rights. 
KEYWORDS: Non-State Actors; Democracy; Internet; Political Reform.

\section{INTRODUÇÃO}

Desde a década de 90, com a difusão da Internet e a globalização da informação, o mundo assiste uma grande e intensa transformação que se reflete nos mais diferentes aspectos: social, político, econômico, científico e cultural.

A expansão do uso da Internet nos últimos anos, em especial se considerado seu estímulo pelo processo de globalização, trouxe consigo aspectos positivos e negativos para a sociedade, e passou a ter papel preponderante no meio de informação, comunicação e no exercício da cidadania.

Paralelamente à evolução tecnológica, os gigantes digitais têm assumido o papel de protagonista e de articuladores desse sistema. O rádio e a televisão, consideradas vias tradicionais de acesso à informação, estão perdendo gradativamente espaço para a Internet, que vem sendo utilizada como fonte de informação, tornando-se parte integral da vida dos cidadãos, da atividade política e da atuação de seus representantes.

Por outro lado, abriu-se espaço para fake news, discussões forjadas e a automatização de ferramentas de publicação na Internet possibilitou o surgimento e a propagação de robôs, na maioria das vezes operacionalizadas do exterior, e que agora dominam parte da vida nas redes sociais e participam ativamente das discussões políticas nacional.

Neste cenário estão as empresas do Vale do Silício, que além de concentrarem valores econômicos em proporções sem precedentes, avaliam, classificam e orientam os comportamentos e atenções dos usuários, direcionando o acesso à informação, os debates políticos e a tomada de decisão dos cidadãos com relação ao voto.

Para tanto analisar essa problemática, a pesquisa é composta por cinco seções. Primeiramente analisar-se-á a trajetória da democracia, desde o sistema de governo ateniense até os dias atuais, ressaltando o valor da liberdade. Em um 
segundo momento, abordar-se-á a reforma política estabelecida pela Lei oㅡ 13.488/2017, que legalizou a propaganda eleitoral na modalidade de "impulsionamento de conteúdo", que consiste em modelo de negócio de grandes empresas de tecnologia localizadas no exterior. Posteriormente, analisar-se-á a comprovada atuação de robôs (bots) como ferramentas utilizadas para gerar um determinado movimento e atribuindo uma dimensão irreal a determinadas notícias, passando para a reflexão sobre a (ir)responsabilidade dos provedores de aplicação de internet por danos decorrentes do conteúdo postado. Por fim, aborda os denominados de "atores não-estatais", analisando a influência que exercem nas políticas globais e interna dos países.

Para avalizar as consequências negativas do protagonismo das gigantes digitais estrangeiras na democracia brasileira, a pesquisa vale-se do método de abordagem dedutivo, por meio de pesquisa bibliográfica e documental.

\section{SOBRE A IDEIA DE DEMOCRACIA}

Desde a Grécia Antiga, com a adoção do regime denominado "democracia ateniense", até os dias atuais, a política no mundo ocidental percorreu um longo e difícil caminho.

No sistema de governo instaurado por Clístenes em 508 a.C., os cidadãos de Atenas passaram a decidir diretamente em assembleia geral sobre os assuntos concernentes à cidade. ${ }^{1}$ Todos aqueles que integravam um "demo", dirigido por um "demarca", participavam das assembleias. Por esse motivo, o novo regime passou a se chamar demokratia, ou seja, governo do "demos".

A democracia ateniense, no entanto, era elitista, por ser limitada aos cidadãos livres maiores de 18 anos e nascidos em Atenas. As mulheres, os estrangeiros (Мع́тоıко) e os escravos estavam excluídos da participar das Assembleias.

\footnotetext{
${ }^{1}$ Clístenes, considerado o "pai da Democracia", liderou uma revolta popular contra o último tirano grego, Hípias, que governou entre 527 a.C. e 510 a. C. Após esse evento, Atenas foi dividida em dez unidades denominadas chamadas "demos", que era o elemento principal dessa reforma.
} 
De acordo com Orides Mezzaroba (2018, p. 161-162), o modelo ateniense garantiu:

a) a isonomia ou igualdade de justiça para todos os cidadãos, sem qualquer distinção de classe, grau e riqueza; b) a isotimia, que abolia toda e qualquer forma de títulos ou funções hereditárias o que possibilitava o livre acesso de qualquer cidadão ao exercício das funções públicas; e c) a isogaria, que garantia o direito do uso da palavra, isso é, a igualdade de todos os cidadãos, para manifestar-se nas assembleias populares a fim de debater publicamente os assuntos do governo.

Assim, destacam-se dois princípios fundamentais para pertencer ao espaço da polis, na forma de governo democrática: liberdade e a igualdade. Ou seja, a liberdade de expressão, conquistada com o direito de discordar do Poder, e a igualdade de direitos, possibilitando-se o acesso do cidadão a esse Poder. O homem somente poderia exercer sua função política em liberdade, e só podia ser livre entre seus pares.

O modelo político de democracia ateniense influenciou as sociedades que a sucederam, refletindo nas cartas de direitos constitucionais, os mais básicos compromissos da democracia: a liberdade e a igualdade dos seus cidadãos (BOBBIO, 1997, p. 8). Concebidos na antiguidade, esses ideais, resistiram à evolução da sociedade e ainda hoje são considerados os princípios cardeais da democracia moderna. A esses valores acrescentou-se outros - como o respeito aos direitos fundamentais e o cuidado ao princípio democrático - que completam o aspecto moderno do sistema político democrático.

Para analisar de forma didática a evolução da democracia, pode-se destacar as seguintes fases: a) democracia direta, onde os membros do grupo social deliberam diretamente; b) democracia representativa, em que somente a vontade do representante terá valor jurídico como vontade expressa do representado; c) democracia representativa partidária, em que o papel de intermediação entre representantes e representados passa a ser desempenhado pelos partidos políticos; e d) democracia de partidos (ou Estado de partidos) ${ }^{2}$, que além de medir os interesses

${ }^{2}$ Este último modelo é defendido por Orides Mezzaroba (2018, p. 163) 
dos órgãos representativos e dos representados, também funcionam como fator decisivo de mediação entre os cidadãos e os representantes do Partidos em razão do mandato partidário. O representante, desta forma, perde o seu caráter de exclusividade na atividade de representação, que é confiada ao Partido como organização.

Segundo José Bernardo Toro (2005, p. 27):

\begin{abstract}
A democracia é uma decisão da sociedade. É, portanto, o espaço por excelência da liberdade, só possível quando resultante de um acordo mútuo, do cumprimento e do respeito àquilo que foi produto de uma decisão livre, ou seja, de um acordo fundado coletivamente. Uma sociedade começa a ser livre e autônoma quando ela mesma for responsável por estabelecer a ordem social e política que quer viver, cumprir e proteger para a dignidade de todos.
\end{abstract}

De acordo com Rogério Gesta Leal (2018, p. 780-781), há determinados valores e regras da democracia que se configuram como conquistas históricas da humanidade - heranças e tradições da matriz democrática -, condizentes à natureza humana, no sentido de enaltecê-la e aprimorá-la à máxima potência, afigurando-se impossível, sob pena de retrocesso da condição humana, desconstituí-las.

É igualmente necessário assimilar ao conceito de democracia, a importância do sistema de direitos e obrigações que, além de definirem a própria democracia historicamente constituída, instituem premissas a partir das quais ela deve se desenvolver. Isso tem ocorrido não por imposição de tradições ancestrais, mas pelas razões de justificação que as edificam e sustentam. Por essa razão, não podem ser usurpadas ou extraídas de qualquer modelo atual de democracia, pois isto significaria negar sua própria existência (LEAL, 2018, p. 783).

Importante destacar que a presença do instituto da representação política em determinado país, não se constitui, por si só, exclusiva garantia democrática. A existência mal ou bem-acabada dos mecanismos representativos pode ser vislumbrada em qualquer modalidade de Estado, mesmo os não-democráticos. Essa situação ocorreu no Regime Militar no Brasil, de 1964 a 1984, em que a representação política não fora suprimida, e partidos políticos cumpriam sua função representativa formal (MEZZAROBA, 2018, p. 163). 
De igual forma, a vontade de uma maioria, por si só, não implica em um modelo de democracia justo. Segundo Ronald Dworkin (2006, p. 26 - 27):

\begin{abstract}
A democracia é um governo sujeito às condições - podemos chama-las de condições "democráticas" - de igualdade de status para todos os cidadãos. Quando as instituições majoritárias garantem e respeitam as condições democráticas, os veredictos dessas instituições, por esse motivo mesmo, devem ser aceitos por todos. Mas quando não o fazem, ou quando essa garantia e esse respeito mostram-se deficientes, não se pode fazer objeção alguma, em nome da democracia, a outros procedimentos que garantam e respeitem as condições democráticas.
\end{abstract}

O objetivo da democracia é que as decisões políticas sejam "tomadas por instituições políticas cuja estrutura, composição e modo de operação dediquem a todos os membros da comunidade, enquanto indivíduos, a mesma consideração e o mesmo respeito" (DWORKIN, 2006, p. 26).

A democracia deve, em última análise, traduz a forma de exercício da função governativa em que a vontade soberana do povo decide, direta ou indiretamente, todas as questões do governo, de tal sorte que o cidadão seja sempre o titular e o objeto de todo poder legítimo (BONAVIDES, 2004, p. 480). Assim, o que torna um Estado democrático é o comprometimento dos órgãos representativos com a democracia.

\title{
2.1 VALORES DA DEMOCRACIA: A LIBERDADE
}

É possível afirmar que o conceito de democracia é sempre relacional, ou seja, é constituída por valores, como liberdade, igualdade, autonomia individual, participação política etc., e formata-se a partir de outros conceitos constitutivos da política, e das relações sociais e institucionais.

Para Bobbio (1986, p. 83-84), a lógica desses valores é que, em uma democracia e em um governo de todos, é necessário que suas informações sejam claras, pois se trata de um governo público feito para decisões públicas, para que os cidadãos possam acompanhar, analisar e tomar decisões. O governo na democracia deve ser visível, ou seja, feito para todos. 
O acesso à informação na democracia, é, portanto, uma das principais bases valorativas desse modelo político e anda pari passu com a transparência. Dentro desta lógica, a circulação de conteúdo durante o processo eleitoral é vital para o acesso à informação, livre manifestação e a formação de opiniões dos eleitores.

Não há como negar a crescente influência da Internet no processo eleitoral, seja na veiculação de propagandas por candidatos, partidos e coligações, ou no exercício de direitos constitucionais de livre manifestação do pensamento dos eleitores, usuários da rede. As redes sociais exerceram, sem dúvida, um papel positivo na difusão dos debates políticos. Impedir ou limitar o acesso à rede ${ }^{3}$ durante o processo eleitoral viola o processo democrático. A atenção, no entanto, deve se voltar à manipulação da informação por meio desta tecnologia. ${ }^{4}$

As fake news são enganosas, se revestem de diversos artifícios para enganar o leitor buscando sua curiosidade e difusão daquele conteúdo. Não é uma ficção, é mentira revestida de artifícios que the conferem aparência de verdade sendo capaz de produzir efeitos. (RAIS, 2018, p. 69)

Ademais, a atuação de perfis automatizados (robôs) promove a desinformação, manipula o debate público e determina de forma consistente os rumos do país. E, neste cenário, os gigantes digitais do Vale do Silício, que representam os principais capitais em bolsa de valores do mundo, tem ocupado um papel decisivo.

\footnotetext{
3 O Conselho de Direitos Humanos da Organização das Nações Unidas (ONU) editou, em 2012, a Resolução A/HRC/20/L.13, denominada de The promotion, protection and enjoyment of human rights on the Internet, que reconhece 0 acesso à internet como garantia à a liberdade de expressão e informação (RIBEIRO; VINCE, 2016, p. 146-170).

4 David Sánchez Rubio (2018, p. 109-110) sustenta que há um esvaziamento da democracia, reduzindo-a ao espetáculo de eleições e sufrágio universal por meio do voto a cada quatro ou cinco anos, e está concentrado em uma área bem definida, de modo que nos espaços mais influentes, os tecnocratas, os gestores e os governantes tomem suas decisões com seus funcionários, tanto sobre a burocracia pública quanto da burocracia privada (sistemas financeiros e bancários, assim como grandes corporações e empresas multinacionais).
} 


\section{REFORMA POLÍTICA NO BRASIL}

A Internet se apresenta como uma montagem social e tecnológica em que são reconfiguradas com vigor as interações humanas, a constituição das identidades, o sistema econômico, as possibilidades políticas. Em outras palavras, é o poder de ação das sociedades sobre si mesmas. (LOVELUCK, 2018, p. 12)

Com o advento da internet, novas formas de relações sociais se firmaram. Estabeleceu-se um verdadeiro universo virtual, no qual as mais diversas atitudes cibernéticas geram consequências na vida material, concreta, "não virtual" dos sujeitos de direito (TOMEDI; GIBRAN, 2014, p. 291). As opiniões geradas em meio digital de uso coletivos também se tornaram parte integral da vida dos cidadãos ${ }^{5}$.

Em 2018, uma pesquisa do IBOPE Inteligência mostra que mais da metade dos eleitores brasileiros (56\%) afirmam que as mídias sociais têm algum grau de influência na escolha do próximo candidato presidencial. Para $36 \%$, as redes têm muita influência. Os meios digitais exercem ainda mais influência entre o público jovem (eleitorado de 16 a 24 anos) onde as mídias sociais têm $48 \%$ de "muita influência”, contra $41 \%$ da mídia tradicional. (IBOPE INTELIGÊNCIA, 2017). Esses números revelam o potencial alcance da Internet como meio de informação, comunicação e exercício da cidadania.

Os avanços tecnológicos e os efeitos uniformizadores da globalização impõem a atualização de institutos jurídicos nacionais, para que estes não conflitem com a realidade social e para não serem impasse ao bom convívio, inclusive oportunizado pela vanguarda da informática (TOMEDI; GIBRAN, 2014, p. 291).

Reconhecendo essa necessidade, agregado ao uso cada vez mais frente da Internet, a reforma no ordenamento político-eleitoral, trazida pela Lei oㅜ 13.488, de 6

\footnotetext{
${ }^{5}$ A maioria dos adultos nos Estados Unidos (62\%) se informa por meio das redes sociais. No entanto, $64 \%$ afirmam que as notícias falsas que circulam nas redes causam "confusão" sobre fatos e acontecimentos diários. No Brasil, 49\% das pessoas já se informam pela internet. (FGV/DAPP, 2017, p. 9)
} 
de outubro de $2017^{6}$, limitou a duração do horário eleitoral na TV e no rádio ${ }^{7}$, colocando a rede como um dos principais meios de marketing eleitoral.

A reforma de 2017 legalizou, de forma inédita, a propaganda eleitoral paga via Internet, na modalidade de "impulsionamento de conteúdo". Neste sentido, a nova redação dada à Lei das Eleições pelo art. 57-C da Lei no 13.488/2017 determina que, a propaganda eleitoral paga na Internet $^{8}$ continua vedada, com exceção ao impulsionamento de conteúdo (ao qual links patrocinados foram equiparados), mediante determinadas condições.

Art. 57-C. É vedada a veiculação de qualquer tipo de propaganda eleitoral paga na internet, excetuado o impulsionamento de conteúdos, desde que identificado de forma inequívoca como tal e contratado exclusivamente por partidos, coligações e candidatos e seus representantes. (PLANALTO, 2017, grifou-se).

O impulsionamento de conteúdo significa ampliar seu alcance e audiência mediante pagamento a um provedor de aplicação de Internet. É o que ficou estabelecido no art. 32, inciso XIII, da Resolução ํㅡ 23.551, de 18 de dezembro de $2017^{9}$, que dispõe dentre outras questões, sobre propaganda eleitoral em campanha eleitoral nas eleições:

[...] impulsionamento de conteúdo: o mecanismo ou serviço que, mediante contratação com os provedores de aplicação de internet, potencializem o alcance e a divulgação da informação para atingir usuários que, normalmente, não teriam acesso ao seu conteúdo; [...]. (TRIBUNAL SUPERIOR ELEITORAL, 2017)

\footnotetext{
${ }^{6}$ A presente lei alterou o texto da Lei no 9.504, de 30 de setembro de 1997 (Lei das Eleições), que estabelece normas para as eleições.

7 Segundo o artigo 51 da Lei $n^{\circ}$ 13.488/2017: "[...] as emissoras de rádio e televisão e os canais por assinatura mencionados no art. 57 desta Lei reservarão setenta minutos diários para a propaganda eleitoral gratuita [...]".

${ }^{8}$ Seria muitas as formas possíveis de propaganda eleitoral na Internet, como links patrocinados, impulsionamentos de publicações em redes sociais, apresentação de banners em sites e blogs, entre outras a depender da plataforma utilizada e do desenvolvimento tecnológico. (RAIS, et. al., 2018, p. 52) ${ }^{9}$ A Resolução TSE no 23.551, de 18 de dezembro de 2017, que dispõe sobre propaganda eleitoral, utilização e geração do horário gratuito e condutas ilícitas em campanha eleitoral nas eleições, foi republicada no DJE-TSE de 14 de maio de 2018.
} 
Significa, pois, contratar um serviço cujo objetivo é expor determinado conteúdo já publicado de forma gratuita (conteúdo orgânico) a uma audiência mais ampla. Desta forma, o conteúdo impulsionado sempre estará atrelado a um conteúdo orgânico que o antecede. (RAIS, et. al., 2018, p. 52)

O impulsionamento de conteúdo é uma ferramenta utilizada como modelo de negócio por diferentes redes sociais na Internet, na qual Facebook, Twitter e Instagram, figuram como as maiores redes mundiais ${ }^{10}$. E, de acordo com as normas eleitorais brasileira, partidos e candidatos poderão contratar o impulsionamento de conteúdo (uso de ferramentas, gratuitas ou não, para ter maior alcance nas redes sociais).

A circulação de conteúdo por meio de mensagens privadas, aquelas cuja comunicação é limitada ao remetente e destinatários, a semelhança de mensagens de texto (SMS), e-mail, ou ainda por aplicativos como WhatsApp, Messenger, Viber, Skype, entre outros, só podem ser analisadas sob a rubrica de propaganda eleitoral, e sofrer intervenção da Justiça ${ }^{11}$, se nela estiver embutido o conceito de publicidade (RAIS, et. al., 2018, p. 61). Porém, se a mensagem é dirigida a um número limitado de pessoas ou disponibilizada de forma restrita no perfil do usuário, não deve ser considerada propaganda eleitoral, sob pena de censura - restrição às liberdades de pensamento e expressão. ${ }^{12}$

A lei compreende também como forma de impulsionamento a priorização paga de conteúdos em mecanismos de busca como o Google. Ou seja, os "links patrocinados", foram equiparados a conteúdo impulsionado. Assim, de acordo com as alterações trazidas pela Lei no 13.488/2017, "inclui-se entre as formas de impulsionamento de conteúdo a priorização paga de conteúdos resultantes de

\footnotetext{
${ }^{10}$ As regras brasileiras proíbem o impulsionamento feito por pessoa física.

11 Para investigar casos específicos, os Tribunais Regionais Eleitorais (TREs) têm que ser provocados pelos Ministérios Públicos ou partidos políticos.

12 A Resolução no 23.551/2017 dispõe que: "Art. 33. A atuação da Justiça Eleitoral em relação a conteúdos divulgados na internet deve ser realizada com a menor interferência possível no debate democrático (Lei no 9.504/1997, art. 57-J). § $1^{\circ}$ Com o intuito de assegurar a liberdade de expressão e impedir a censura, as ordens judiciais de remoção de conteúdo divulgado na internet serão limitadas às hipóteses em que, mediante decisão fundamentada, sejam constatadas violações às regras eleitorais ou ofensas a direitos de pessoas que participam do processo eleitoral." (TRIBUNAL SUPERIOR ELEITORAL, 2017)
} 
aplicações de busca na internet." (PLANALTO, 2017, art. 26, § 2º). Nessas hipóteses, o link objeto de impulsionamento é exposto de forma prioritária no resultado de pesquisas do provedor de busca contratado, em espaço reservado para publicidade.

Neste sentido, a previsão não só viabiliza que candidatos, partidos e coligações paguem para que suas páginas, perfis e posts sejam mostrados para um maior número de pessoas, como também possibilita que determinado conteúdo seja exibido à um público específico, uma vez que a propaganda eleitoral impulsionada possui alvos predeterminados, estabelecidos com base nas informações que plataformas recolhem nas interações on-line dos usuários.

A premissa é de que a rede deve ser um lugar de debate livre, onde prevaleceria, em tempos de eleição, a opinião dos eleitores, no entanto, essa realidade pode ser agora questionada. Ao permitir o "impulsionamento" pago de conteúdo eleitoral na Internet, bem como o uso de ferramentas digitais disponibilizada pela plataforma contratada, possibilitou-se a manipulação do debate público nas redes sociais, em que, frequentemente, tem a atuação de robôs (bots) para gerar um determinado movimento e atribuindo uma dimensão irreal a determinadas notícias.

Ademais, a permissão de impulsionamento de conteúdos como exceção à proibição de veiculação de propaganda eleitoral paga, limitou o investimento em propagandas eleitorais na rede aos serviços e modelos de negócios das grandes empresas de tecnologia do Vale do Silício, tornando o debate político nas redes sociais ainda mais preocupante e vulnerável.

\section{SOCIAL BOTS NO AMBIENTE POLÍTICO}

Os robôs sociais, em inglês social bots, também chamados de "perfis automatizados", são contas controladas por software, que geram conteúdo artificial e estabelecem interações com não robôs (usuários da Internet), buscando imitar o comportamento humano a ponto de interferir em debates público espontâneos e criar discussões forjadas, por meio de postagem e replicação de mensagens em larga escala. (FGV/DAPP, 2017, p. 6) 
Os robôs frequentemente utilizam as redes sociais ${ }^{13}$ para reproduzir notícias falsas - fake news ${ }^{14}$, compartilhando links como principal mecanismo de propagação, com o objetivo de influenciar determinada opinião sobre uma pessoa ou tema, ou poluir o debate com informações reais, porém irrelevantes. E, no cenário político atual, é comum o uso orquestrado de redes de robôs (botnets) para gerar um determinado movimento, manipulando os trending topics ${ }^{15}$ e atribuindo uma dimensão irreal a determinadas notícias.

Com este tipo de manipulação, os robôs

[...] criam a falsa sensação de amplo apoio político a certa proposta, ideia ou figura pública, modificam o rumo de políticas públicas, interferem no mercado de ações, disseminam rumores, notícias falsas e teorias conspiratórias, geram desinformação e poluição de conteúdo, além de atrair usuários para links maliciosos que roubam dados pessoais, entre outros riscos. (FGV/DAPP, 2017, p. 9)

Um estudo sobre as interferências ilegítimas no debate público ${ }^{16}$ na web feito pela FGV/DAPP (2017, p. 6), aponta que ação de robôs chegou a ser responsável por mais de $10 \%$ das interações no Twitter nas eleições presidenciais de $2014^{17}$.

Pesquisadores da Diretoria de Análise de Políticas Públicas da Fundação Getúlio Vargas (FGV/DAPP, 2017, p. 9) afirmam que ações orquestradas de robôs

13 "Os robôs têm maior facilidade de propagação no Twitter do que no Facebook por uma série de motivos. O padrão de texto do Twitter (140 caracteres) gera uma limitação de comunicação que facilita a imitação da ação humana. Além disso, o uso de @ para marcar usuários, mesmo que estes não estejam conectados a sua conta na rede, permite que os robôs marquem pessoas reais aleatoriamente para inserir um fator que se assemelhe a interações humanas." (FGV/DAPP, 2017, p. 12)

${ }_{14}$ Vale lembrar que o Código Eleitoral dispõe em seu art. 323 que constitui crime: "Divulgar, na propaganda, fatos que sabe inverídicos, em relação a partidos ou candidatos e capazes de exercerem influência perante o eleitorado" (PLANALTO, 1965). A reforma de 2017 avançou na temática, destacando a proibição de perfis falsos: art. 57-B, § $2^{\circ}$ : "Não é admitida a veiculação de conteúdos de cunho eleitoral mediante cadastro de usuário de aplicação de internet com a intenção de falsear identidade" (PLANALTO, 2017)

15 Treding Topics ou TT's são uma lista em tempo real das palavras mais postadas no Twitter em todo o mundo.

${ }^{16}$ O que não cabe afirmar que os atores políticos e públicos sejam responsáveis diretos pelos robôs a seu favor. Diversos grupos de interesse podem se utilizar deste recurso.

17 O estudo aponta ainda que quase $20 \%$ das interações no debate entre os usuários favoráveis a Aécio Neves no segundo turno das eleições de 2014 foi motivado por robôs. Em outro momento político, registrou-se que durante protestos pelo Impeachment, essas interações provocadas por robôs representaram mais de $20 \%$ do debate entre apoiadores de Dilma Rousseff, que usavam significativamente esse tipo de mecanismo. (FGV/DAPP, 2017, p. 6). 
têm sido identificadas em grandes eventos da política nacional e internacional, como as eleições americanas de 2010, a eleição de Donald Trump em 2016 e o plebiscito do Brexit ${ }^{18}$. No Brasil, foram registradas, dentre outras, ocorrências nas eleições de 2014, na aprovação da Reforma Trabalhista e no debate sobre o Impeachment.

Para analisar a disposição de possíveis robôs nas discussões durante as eleições de 2014 , foram selecionados ${ }^{19}$ os tuítes que trataram do debate entre Dilma e Aécio no segundo turno.

De todos as interações no Twitter nas horas analisadas, $11,34 \%$ foram motivadas por tuítes ou retuítes de robôs. Entre os apoiadores de Aécio Neves, porém, essa parcela de interações com contas automatizadas (robôs sendo retuitados por outros robôs ou contas comuns) chegou a 19,41\%. Nas discussões entre perfis em apoio a Dilma, foram 9,76\%. (FGV/DAPP, 2017, p. 18)

Segundo os pesquisadores, o poder de influência deste tipo de conta no debate público também pode ser observado nas discussões no Twitter, no dia da maior manifestação registrada a favor do impeachment. Neste caso,

Pelo menos $10 \%$ das interações sobre o assunto neste dia foram impulsionadas por robôs, ou seja, retuítes de conteúdo originado por conta automatizada. No cluster (grupo) de apoiadores de Dilma Rousseff, essa proporção chegou a 21,43\%. (FGV/DAPP, 2017, p. 20)

No estudo sobre os debates nas redes sociais em decorrência da votação da Reforma Trabalhista pelo plenário do Senado Federal, no dia 11 de julho, detectou-se que $2 \%$ das interações relacionadas a este evento como automatizadas - $3 \%$ das interações contrárias à reforma e 1\% das favoráveis. (FGV/DAPP, 2017, p. 20) 18 Termo originado na língua inglesa resultante da junção das palavras Britain (Grã-Bretanha) e exit
(saída), atribuído à saída do Reino Unido da União Europeia.
19 Não há uma única metodologia para a detecção de robôs em redes sociais. É possível a análise de
links compartilhados para identificar fazendas de links (empresas que administram robôs e vendem
curtidas, retuítes, etc.) e dinâmicas de interações (GHOSH et al, 2012), bem como as atividades, que
tendem a ser menos complexas na variedade de ações que os robôs praticam se comparadas aos
humanos, o que possibilita determinar se perfil é um robô. Para os estudos de casos apresentados, os
pesquisadores da FGV/DAPP escalonaram a quantidade de tuítes gerada por cada um dos 1925
generators. Deste total, 181 produziram pelo menos 100 tuítes cada. Após uma análise manual,
identificaram 83 generators que produzem tuítes automaticamente de maneira programada ou
utilizando a plataforma Twitter através de automação. (FGV/DAPP, 2017, p. 16) 
As interações de contas com tuítes produzidos automaticamente denunciam o uso de robôs no debate político brasileiro, e revelam a necessidade de identificar suas atividades para que possam ser reconhecidos os debates legítimos, daqueles que são forjados.

Neste sentido, a Lei no 13.488/2017 tentou evitar o uso de bots que inflamam curtidas e $\mathrm{o}$ alcance de posts, proibindo qualquer outra tática de impulsionamento que não seja disponibilizada pela plataforma contratada.

\begin{abstract}
Art. 57-B. § $3^{\circ}$. É vedada a utilização de impulsionamento de conteúdos e ferramentas digitais não disponibilizadas pelo provedor da aplicação de internet, ainda que gratuitas, para alterar o teor ou a repercussão de propaganda eleitoral, tanto próprios quanto de terceiros. (PLANALTO, 2017, grifou-se)
\end{abstract}

Em outras palavras, consentiu-se que os provedores de aplicação de Internet contratados - e tão somente eles - utilizem suas ferramentas digitais, qual seja, os robôs.

A definição de "provedores de aplicação de Internet", utilizado pelo art. 32, da Resolução no 23.551/2017, em consonância com o adotado pelo art. 5ำ do Marco Civil da Internet de 2014, é ampla e abrangente, podendo ser entendido que todo provedor que dispõe de alguma funcionalidade na Internet se enquadra neste conceito:

[...] XVII - provedor de aplicação de internet: a empresa, organização ou pessoa natural que, de forma profissional ou amadora, forneça um conjunto de funcionalidades que podem ser acessadas por meio de um terminal conectado à internet, não importando se os objetivos são econômicos [...]

Ou seja, todas as empresas que disponibilizam tais funcionalidades são enquadradas na categoria de "provedores de aplicação de Internet" ${ }^{20}$. Assim, as

20 Diferenciam-se da categoria de "provedor de aplicação de Internet": o "provedor de acesso ou de conexão à Internet: a pessoa jurídica fornecedora de serviços que consistem em possibilitar o acesso de seus consumidores à internet" (art. 32, XVI, Resolução n 23.551/2017); e o "provedor de conteúdo na internet: a pessoa natural ou jurídica que disponibiliza na internet as informações criadas ou desenvolvidas pelos provedores de informação (ou autores), utilizando servidores próprios ou os serviços de um provedor de hospedagem para armazená-las" (art. 32, XVIII, Resolução no 23.551/2017). 
mídias sociais (Facebook, Twitter, Linkedln, etc), as plataformas para assistir e compartilhar vídeos (Youtube, etc), os serviços de e-mail ou correios eletrônicos (Hotmail, Gmail, etc.) e as páginas para fazer blogs, são exemplos de funcionalidades oferecidas pelas empresas aos usuários já conectados à internet.

Com esse raciocínio, tem-se que a lei eleitoral, ao autorizar o impulsionamento de conteúdos e o uso de ferramentas digitais disponibilizada pela plataforma contratada - provedores de aplicação de Internet -, conferiu às empresas estrangeiras, o poder de priorizar o discurso político no país.

\section{A (IR)RESPONSABILIDADE DOS PROVEDORES DE APLICAÇÃO DE INTERNET POR DANOS DECORRENTES DO CONTEÚDO POSTADO}

A produção de conteúdo manipulado, disseminados pela intensa participação de robôs no ambiente virtual, cumulado com as mudanças de cenário legislativo eleitoral, aqueceu o mercado dos big data ${ }^{21}$ e de marketing digital, atingindo os processos políticos, gerando risco de contaminar o debate público legítimo na democracia.

As interações de contas com tuítes produzidos automaticamente pela plataformas digitais estrangeiras, autorizadas a atuar no país, denunciam o uso de robôs no debate político brasileiro. No entanto, a identificação de robôs nas redes e a responsabilização não é uma tarefa fácil. Para detectar se um perfil pertence a um usuário real ou falso, são feitas, a partir da coleta de metadados, composições de múltiplas características inter-relacionados e de padrões de comportamento. ${ }^{22}$

\footnotetext{
21 "A multinacional britânica Cambridge Analytica, uma empresa que, utilizando abordagens de cunho psicológico e big data, analisa o comportamento de eleitores e consumidores. [...] A estratégia utilizada é traçar a personalidade dos indivíduos com base em preceitos clássicos de psicologia e nos rastros digitais que deixamos diariamente, como perfis em redes sociais, GPS de locais visitados, dados de uso dos serviços públicos e compras online. A partir daí, eles dizem serem capazes de produzir mensagens moldadas em nível praticamente individual." (MARREIRO; ROSSI, 2017)

22 São fatores considerados relevantes para se identificar robôs a partir do padrão comportamental do perfil: a - pouca ou inexistente - interação de reciprocidade entre usuários, a proporção e a correlação entre perfis seguidos e perfis que seguem o usuário, menções e repetição de hashtags, conteúdo ${ }^{22}$ e linguagem, tempo médio de produção de tweets etc. (FGV/DAPP, 2017, p. 13-15).
} 
No que tange às responsabilidades dos provedores de aplicação de Internet, decorrentes do impulsionamento e do uso de plataformas no âmbito eleitoral, a Resolução 23.551/2017 do TSE segue os parâmetros legais estabelecidos no Marco Civil da Internet, que constitui verdadeira lei "guarda-chuva", definindo princípios, fundamentos, objetivos, direitos e deveres do seu uso.

No que tange à responsabilização civil por danos decorrentes do conteúdo criado e/ou divulgados por usuários, como regra, os provedores de aplicação de Internet somente podem ser responsabilizados por atos de usuários na hipótese de descumprimento de ordem jurídica específica. É o que dispõe o Marco Civil da Internet:

Art. 19. Com o intuito de assegurar a liberdade de expressão e impedir a censura, o provedor de aplicações de internet somente poderá ser responsabilizado civilmente por danos decorrentes de conteúdo gerado por terceiros se, após ordem judicial específica, não tomar as providências para, no âmbito e nos limites técnicos do seu serviço e dentro do prazo assinalado, tornar indisponível o conteúdo apontado como infringente, ressalvadas as disposições legais em contrário.

No mesmo sentido, o teor do art. 57-B, $\S 4^{0}$ da Lei das Eleições ${ }^{23}$ prevê que a responsabilidade do provedor de aplicação de Internet por danos decorrentes do conteúdo impulsionado, dá-se apenas em caso de descumprimento de ordem judicial de remoção de conteúdo.

A intenção do legislador foi de atribuir obrigações em matéria de impulsionamento aos atores próprios envolvidos no processo eleitoral, ou seja, aos candidatos, partidos ou coligações. Os provedores, a partir desta perspectiva, não são atores próprios do processo eleitoral.

O poder de moldar o discurso político de seus candidatos de acordo com o público a quem direcionam sua publicidade distorce o discurso democrático, e esse

${ }^{23} \mathrm{O}$ texto do art. 57-B, $\S 4^{\circ}$, foi incluído pela Lei $n^{\circ} 13.488$, de 2017: "O provedor de aplicação de internet que possibilite o impulsionamento pago de conteúdos deverá contar com canal de comunicação com seus usuários e somente poderá ser responsabilizado por danos decorrentes do conteúdo impulsionado se, após ordem judicial específica, não tomar as providências para, no âmbito e nos limites técnicos do seu serviço e dentro do prazo assinalado, tornar indisponível o conteúdo apontado como infringente pela Justiça Eleitoral. 
cenário pede medidas urgentes que reforcem a privacidade, a liberdade de informação e escolha dos eleitores e confiram mais transparência às campanhas políticas.

Além de ferramentas que possibilitem monitorar tanto a publicidade direcionada como a manipulação de algoritmos e o uso de bots, partidos, coligações e candidatos deveriam divulgar uma lista de conteúdos impulsionados por rede social, a quantia utilizada, bem como informações sobre as empresas contratadas. Por outro lado, as empresas devem ser transparentes sobre a lógica do algoritmo e as priorizações do conteúdo eleitoral disseminado.

\section{OS ATORES NÃO-ESTATAIS A SUA INFLUÊNCIA NA DEMOCRACIA}

A visão monolítica das relações internacionais em que Estados eram os únicos sujeitos do direito internacional começou a se alterar com os eventos do início do século XX, notadamente com a Primeira e Segunda Guerras Mundiais, quando consolidam-se as primeiras organizações internacionais intergovernamentais, e estas passam a integrar o rol de atores tradicionais na cena internacional.

Segundo Gionani Olsson e Eduardo Baldissera Carvalho (2017, p. 341), atualmente existem os denominados "atores tradicionais", os "novos atores" e os "atores emergentes": Entre os "atores tradicionais", os Estados representam os pilares de estabilização das relações sociais, uma vez que concentram a regulação da sociedade no âmbito territorial e garantem bens da vida como a segurança, a dignidade e a liberdade, portanto continuam exercendo importante papel para os indivíduos; e as organizações internacionais intergovernamentais, decorrem da performance exterior dos Estados, sendo comumente criadas como mecanismos de cooperação, tendo como mais notório exemplo, a Organização das Nações Unidas $(\mathrm{ONU})$. Os "novos atores", por sua vez, particionam-se em organizações internacionais não-governamentais e em empresas transnacionais, possuindo, como elemento caracterizador, a aptidão de inflexionar enorme coeficiente da população mundial. Já os "atores emergentes" são líquidos, voláteis e fugidios, traduzindo-se como entidades de grande amplitude operativa, como por exemplos: os movimentos 
sociais, os partidos políticos, os sindicatos, a mídia, o crime organizado, o terrorismo, entre outros.

Apesar de influenciam o atual recorte econômico e político global, os "novos atores" e os "atores emergentes" possuem como característica comum, a atuação sem vínculo direto com os Estados, portanto, denominados de "atores não-estatais". Ou seja, são agentes que, não pertencem a estrutura estatal, atuam em determinado plano e produzem efeitos (GARCEZ; FREITAS, 2015, p. 231).

A participação de atores não-estatais nas políticas internas dos países, no entanto, altera a dinâmica jurídica global, e afetam a efetividade dos compromissos assumidos pelos Estados para com os direitos humanos, dentre os quais estão os compromissos básicos da democracia: a liberdade e a igualdade dos seus cidadãos.

\begin{abstract}
A capacidade que esses atores possuem para concentrar recursos econômicos, transpor marcos regulatórios e influenciar políticas estatais constitui o que contemporaneamente se nomeia de descolamento da governança do núcleo do governo, que traduz o fenômeno que atingiu os Estados e retirou-lhes a capacidade de ditar os rumos nacionais com exclusividade (OLSSON; SALLES, 2017, p. 343).
\end{abstract}

Com essa atual agenda, os Estados perdem, mais uma vez, seu influente papel no âmbito econômico e político, e são desafiados a manter a estabilidade das relações sociais, ainda que diante da forte atuação de empresas multinacionais, ONGs, movimentos sociais, partidos políticos, mídia (social bots, fake-news), crime organizado etc., que emergiram no cenário jurídico internacional nas últimas décadas, impulsionados, em grande medida, pela facilidade da internet e das novas tecnologias.

A influência real desses atores não-estatais nas políticas globais e interna dos países, revelam a urgente necessidade de mudança na dinâmica do poder, que deve ser vista como o ponto culminante de um processo de desenvolvimento e expansão tanto para a ampliação do conceito de sujeitos do direito internacional quanto para os objetos de direito internacional - os tópicos de regulamentação jurídica internacional - que se expandiram e se diversificaram (BEDERMAN, 2008).

Embora seja inegável que tenham grande capacidade de desenvolverem a economia dos países, ainda não existem mecanismos de controle disposição da 
sociedade para contestar suas práticas no âmbito global. Diferentemente do que ocorre com os Estados, que podem responsabilizados internacionalmente por uma ação ou omissão, esses novos atores não-estatais são fugidios e líquidos.

\subsection{O MODELO DE NEGÓCIO DOS OPERADORES DE APLICAÇÃO DE INTERNET DO VALE DO SILÍCIO E A FRAGILIZAÇÃO DA DEMOCRACIA}

O Silicon Valley, traduzido para o português como Vale do Silício, é uma região que abrange várias cidades do estado da Califórnia, Estados Unidos, no sul da baía de São Francisco, como Palo Alto e Santa Clara, e na qual está situado um conjunto de empresas inovadoras.

A industrialização da região se deu no início de 1890, mas o impulso para o desenvolvimento ocorreu com a Segunda Guerra Mundial e, principalmente, durante a Guerra Fria, devido à corrida armamentista e aeroespacial.

O termo "Vale do Silício", era usado ocasionalmente por cidadãos que faziam viagens ao Vale, em referência ao "silício" como principal elemento químico usado na composição dos chips fabricados por empresas com sede na baía de São Francisco, que na época já abrigava nomes promissores da indústria, como a Advanced Micro Devices (AMD) e a INTEL. O termo se popularizou em 1971, em uma série de artigos "Silicon Valley USA", escrita pelo Don Hoefler para o Electronic News. (HOEFLER, 1971)

Atualmente, tem-se que o Vale do Silício, bolsão das inovações da informática, abriga empresas que hoje figuram entre as maiores do mundo. Cita-se, dentre muitas outras: Apple, Google, Facebook, NVIDIA Corporation, Electronic Arts, Symantec, Advanced Micro Devices (AMD), eBay, Maxtor, Yahoo!, Hewlett-Packard (HP), Intel e Foursys.

Os interesses de alguns dessas gigantes digitais, foram validados pela reforma eleitoral brasileira de 2017 que legalizou, de forma inédita, a propaganda eleitoral paga via Internet, na modalidade de "impulsionamento de conteúdo", ferramenta utilizada como modelo de negócio dos provedores de aplicação de 
Internet. Ou seja, o "impulsionamento", favoreceu o modelo de negócios de empresas do Vale do Silício, que operam seus robôs do exterior.

São funcionalidades oferecidas por essas empresas aos usuários já conectados à internet: as mídias sociais (Facebook, Twitter, Linkedln, etc), as plataformas para assistir e compartilhar vídeos (Youtube, etc), os serviços de e-mail ou correios eletrônicos (Hotmail, Gmail, etc.) e as páginas para fazer blogs. A lei também equiparou os links patrocinados em mecanismos de busca como o Google a conteúdo impulsionado. E, ao possibilitar que os provedores de aplicação de Internet contratados utilizem suas ferramentas digitais, a lei legitima o uso de robôs.

Em outras palavras, a lei eleitoral, ao autorizar a contratação por partidos políticos de serviços de impulsionamento de conteúdos e o uso de ferramentas digitais disponibilizada pela plataforma digitais - provedores de aplicação de Internet -, conferiu às empresas estrangeiras, a possibilidade de manipulação do discurso político no Brasil.

\section{CONCLUSÃO}

O artigo analisou, por intermédio de pesquisa bibliográfica e documental, a reforma política realizada em 2017 no Brasil, tendo em vista o acentuado protagonismo da mídia, de partidos políticos e das empresas estrangeiras e essas implicações para a democracia brasileira.

As normas eleitorais, objetivam, regra geral, conferir lisura e equilíbrio ao processo eleitoral, em respeito aos princípios democráticos, à liberdade de expressão e informação, e ao direito de escolha do candidato. No entanto, não é o que se registrou com a reforma política no Brasil - Lei oㅜ 13.488, de 6 de outubro de 2017 e Resolução 23.551/2017 do TSE - que favoreceu o modelo de negócios do Vale do Silício.

Buscando atender a realidade do uso cada vez mais frente da Internet, a reforma no ordenamento político-eleitoral brasileiro, limitou a duração do horário eleitoral na TV e no rádio, colocando a rede como um dos principais meios de 
marketing eleitoral. Legalizou, no entanto, a propaganda eleitoral paga via Internet, na modalidade de "impulsionamento de conteúdo", aos quais os links patrocinados foram equiparados e as ferramentas (robôs) foram autorizadas.

No entanto, considerando que esse é o modelo de negócio das grandes empresas de provedores de aplicação de Internet situadas no estado da Califórnia, nos Estados Unidos, conclui-se que essas empresas estrangeiras são as contratadas para realizar as campanhas eleitorais.

Em decorrência da falta de transparências nas ações das empresas provedores de aplicativos de Internet, supõe-se que pode haver manipulação do debate público nas redes sociais, em que, frequentemente, tem a atuação de robôs (bots) para gerar movimentos e atribuir dimensão irreal a determinadas notícias, reais ou irreais (fakenews).

Registra-se que a utilização da rede em si não é letal, mas é possível afirmar que o uso de ferramentas demonstra seu potencial danoso para disseminar informações, que ausente de transparência, consistem em uma ameaça real para a disputa política e o debate público. O reflexo na democracia, portanto, é inevitável, uma vez que o processo de formação de consensos, a seleção de representantes e as agendas de governo podem ser manipulados.

Presume-se, também, que as campanhas mais ricas terão acesso aos serviços oferecidos pelas grandes empresas de provedores de aplicação de Internet, gerando, portanto, desigualdade nas candidaturas.

Ademais, em razão dos provedores de aplicação de Internet operarem, em sua grande maioria, em território estrangeiro, surge a hipótese de que atores, alheios aos nacionais, estejam conduzindo, através da manipulação de instrumentos pelas redes, reflexões alienadas aos autênticos problemas do Brasil.

Neste sentido, instituir mecanismos para se distinguir dado real do manipulado, é fundamental tanto para o governo como para a sociedade civil, em defesa das liberdades civil e direitos políticos.

Para que as redes sociais sejam um espaço democrático legítimo de opinião e informação, é importante um esforço contínuo em desenvolver e aprimorar tecnologias de detecção e inibição desse fenômeno, aliado à transparência da rede e 
responsabilização das empresas, que pode ser uma exigência para a contratação desses serviços de automatização, evitando-se, assim, a propagação de "desinformação".

\section{REFERÊNCIAS}

A INTERNET transforma a política. Le Monde Diplomatique Brasil. Transmitido ao vivo em 26 jul. de 2018. Duração: 61'03". Disponível em: https://www.youtube.com/watch?v=_vm-67ATDSc. Acesso em: 07 mar. 2019.

BEDERMAN, David J. Diversity and Permeability in Transnational Governance. In: Emory Public Law Research, vol. 57, february, 2008, paper №. 08-31, p. 171-202. Disponível em: http://dx.doi.org/10.2139/ssrn.1092423. Acesso em: 10.fev.2019.

BELLAMY, Richard. Democracy without democracy? Can the EU's democratic 'outputs' be separated from the democratic 'inputs' provided by competitive parties and majority rule? In: Journal of European Public Policy, v. 17:1, 2010, p. 2-19.

BOBBIO, Norberto. Igualdade e liberdade. 3. ed. Tradução de Nelson Coutinho. Rio de Janeiro: Ediouro, 1997.

O futuro da democracia: uma defesa das regras do jogo. Tradução de Marco Aurélio Nogueira. Rio de Janeiro: Paz e Terra, 1986.

BONAVIDES, Paulo. A constituição aberta. 3. ed. São Paulo: Malheiros, 2004.

BRITO, Francisco et. al. Detecting social-network bots based on multiscale behavior analysis. In: SECURWARE 2013: The Seventh International Conference on Emerging Security Information, Systems and Technologies. Disponível em: https://www.thinkmind.org/download.php?articleid=securware_2013_4_30_301. 46. Acesso em: 10 jan. 2019.

CANOTILHO, J. J. Gomes. Direito Constitucional e Teoria da Constituição. 7.ed. Coimbra: Almedina, 2003.

; MOREIRA, Vital. Os poderes do Presidente da República. Coimbra: Coimbra Editora, 1991.

DWORKIN, Ronald. O direito da liberdade: uma leitura moral da Constituição norteamericana. 1.ed. São Paulo: Martins Fontes, 2006.

FUNDAÇÃO GETÚLIO VARGAS. Robôs, redes sociais e política no Brasil: estudo sobre interferências ilegítimas no debate público na web, riscos à democracia e 
processo eleitoral de 2018. Coordenação de Aurélio Ruediger. Rio de Janeiro: FGV, DAPP, 2017.

GARCEZ, Gabriela Soldano; FREITAS, Gilberto Passos de. Governança, globalização e atores não estatais: uma análise sob a perspectiva do direito internacional. In: SCIENTIA IURIS, Londrina, v. 19, n. 2, dez.2015, p. 223-240, DOI: 10.5433/2178-8189.2015v19n2p223

GHOSH, S., et. al. Understanding and combating link farming in the twitter social network. In: Proceedings of the 21st International Conference on World Wide Web - WWW 2012, p. 61. ACM Press, New York, 2012. Disponível em: http://twitter.mpisws.org/spam/pubs/twitterSpam_WWW2012.pdf Acesso em: 09 fev. 2019.

HOEFLER, Don C. Silicon Valley USA, Electronic News, 11.jan.1971. Disponível em: https://www.computerhistory.org/revolution/digital-logic/12/328/1401. Acesso em: 03.fev.2019.

IBOPE INTELIGÊNCIA. Redes sociais e mídias tradicionais são as fontes de informação com mais influência na escolha do presidente em 2018, 13.jun.2017. Disponível em: http://www.ibopeinteligencia.com/noticias-e-pesquisas/redes-sociaise-midias-tradicionais-sao-as-fontes-de-informacao-com-mais-influencia-na-escolhado-presidente-em-2018/. Acesso em: 01.fev.2019.

LE MONDE DIPLOMATIQUE. Entre trolls, robôs e ativadores: as eleições na internet. Disponível em: http://diplomatique.org.br/entre-trolls-robos-e-ativadores-aseleicoes-na-internet/. Acesso em 12 de agosto de 2017.

LEAL, Rogério Gesta. Demarcações conceituais da democracia contemporânea: a vitalidade renovada de Ronald Dworkin. In: Revista Novos Estudos Jurídicos, v. 23, n. 3, set-dez 2018, p. 777-797. DOI http://dx.doi.org/10.14210/nej.v23n3.p777-797

LOVELUCK, Benjamin. Redes, liberdades e controle: uma genealogia política da internet. Tradução de Guilherme João de Freitas Teixeira. Petrópolis, RJ: Vozes, 2018.

MARREIRO, Flávia; ROSSI, Marina. O marqueteiro brasileiro que importou o método da campanha de Trump para usar em 2018, 15.out.2017. In: El país. Disponível em: https://brasil.elpais.com/brasil/2017/10/11/politica/1507723607_646140.html. Acesso em: 03.fev.2019.

MEZZAROBA, Orides. Teoria geral do direito partidário e eleitoral. Florianópolis: Qualis, 2018.

OLSSON, Giovanni; SALLES, Eduardo Baldissera Carvalho. O papel dos atores estatais e não estatais no desenvolvimento sustentável global: uma introdução. 
Revista Direito e Justiça - Reflexões Sociojurídicas, ano XVII, № 28, maio 2017, p 333-346.

PLANALTO. Lei no 12.965, de 23 de abril de 2014. Estabelece princípios, garantias, direitos e deveres para o uso da Internet no Brasil. Disponível em: http://www.planalto.gov.br/ccivil_03/_ato2011-2014/2014/lei//12965.htm. Acesso em: 25 fev. 2019.

PLANALTO. Lei no 13.488, de 6 de outubro de 2017. Altera as Leis nos 9.504, de 30 de setembro de 1997 (Lei das Eleições), 9.096, de 19 de setembro de 1995, e 4.737, de 15 de julho de 1965 (Código Eleitoral), e revoga dispositivos da Lei no 13.165, de 29 de setembro de 2015 (Minirreforma Eleitoral de 2015), com o fim de promover reforma no ordenamento político-eleitoral. Disponível em: http://www.planalto.gov.br/ccivil_03/_ato2015-2018/2017/lei/L13488.htm. Acesso em: 10 fev. 2019.

PLANALTO. Lei no 4.737, de 15 de julho de 1965. Institui o Código Eleitoral. Disponível em: http://www.planalto.gov.br/ccivil_03/leis/L4737.htm. Acesso em: 10 fev. 2019.

RAIS, Diogo et. al.. Direito eleitoral digital. São Paulo: Thomson Reuters Brasil, 2018.

REDAÇÃO. Tuítes da Folha sobre "bolso" e "bolovo" ativam ação de robôs, que saem em defesa de Bolsonaro, 25 out. 2018. In: Fórum. Disponível em: https://www.revistaforum.com.br/tuites-da-folha-sobre-bolso-e-bolovo-ativam-acaode-robos-que-saem-em-defesa-de-bolsonaro/?fbclid=IwAR3eigM7fbTc6AXOwXGIOr4Lgc2GvXrEyaKFec-7wLd3KRffeQZZOou4M8. Acesso em: 20 fev. 2019.

RIBEIRO, Daniela Menengoti; VINCE, Fernando Navarro. Internacionalização dos direitos: o reconhecimento do acesso à internet como direito humano e sua limitação pelos Estados. In: Teófilo Marcelo de Arêa Leão Júnior; Mauricio de Aquino. (Org.). Sistema Constitucional de Garantia de Direito. Jacarezinho: UENP, 2016, p. 146170.

RUBIO, David Sánchez. Derechos humanos (vaciados), constitucionalismo (oligárquico y de los negocios) y democracia (sin demócratas) en el mundo contemporâneo. Revista da Faculdade de Direito da FMP, v. 13 n. 2, 2018, p. 105140.

TOMEDI, Guilherme Dorigo; GIBRAN, Sandro Mansur. A efetividade da tutela jurisdicional em relação aos estabelecimentos comerciais eletrônicos. Revista Jurídica Unicuritiba, Curitiba, v. 1, n. 34, p. 289-311, jan./mar. 2014. 
TORO, José Bernardo. A construção do público: cidadania, democracia e participação. Seleção de textos e organização, Cristina Duarte Werneck e Nísia Duarte Werneck. Rio de Janeiro: Editora Senac Rio, 2005.

TRIBUNAL SUPERIOR ELEITORAL. Resolução no 23.551, de 18 de dezembro de 2017. Dispõe sobre propaganda eleitoral, utilização e geração do horário gratuito e condutas ilícitas em campanha eleitoral nas eleições. Disponível em: http://www.tse.jus.br/legislacao-tse/res/2017/RES235512017.html. Acesso em: 01 fev. 2019.

VARON, Joana; SANTOS, Bruna. Quem dá mais na campanha eleitoral na internet? Le monde diplomatique, 3.jul.2018, ed. 132. Disponível em: https://diplomatique.org.br/quem-da-mais-na-campanha-eleitoral-nainternet/?fbclid=IwAR1V3AgzEVBAvSIMBjr2X4jMSQsdJMaNZ_ogp1DxpmSZttUC3JXRX7xqsM. Acesso em: 01 fev. 2019. 